\title{
TRADUCIR EL MARTÍN FIERRO, UNA CREDENCIAL CULTURAL PARA FOLCO TESTENA
}

\author{
Sara Jaquelina Iriarte 1 \\ 1Universidade Nacional de Rosário, Rosário, Santa Fé, Argentina
}

\begin{abstract}
Resumen: En los intersticios entre literatura y vida, Folco Testena forja su autofiguración de traductor en la introducción al Martín Fierro que preparó para acompañar su primera versión al italiano de la obra de José Hernández. Su relato en primera persona revela lo íntimo a la vez que da cuenta de las coyunturas sociohistóricas que marcaron la labor intelectual desarrollada por los inmigrantes en la cosmopolita Buenos Aires de principios del siglo XX. Traducir el Martín Fierro se presenta, bajo la forma de una historia de autosuperación, como la oportunidad para obtener una credencial cultural en un medio de hostilidad al extranjero y de censura política. El objetivo del presente artículo es poner en circulación un texto de difícil acceso y contribuir a completar el cuadro de la historia de la traducción poniendo en foco a los sujetos sociales que la protagonizan.
\end{abstract}

Palabras-clave: Autofiguración; Folco Testena; Traducciones de Martín Fierro; Revista Nosotros; Migración Italiana

\section{TRANSLATING MARTÍN FIERRO - FOLCO TESTENA'S CULTURAL CREDENTIAL}

\begin{abstract}
In the introduction to Martín Fierro, published to accompany his first rendering of José Hernandez's work into Italian, Folco Testena forges his self-figuration as a translator within the interstices between literature and life. This first-person narration not only dives deep into the realms of intimacy, but also reveals the socio-historical circumstances around which immigrants carried out intellectual work in early 20th century, cosmopolitan Buenos Aires. In the shape of a tale of self-improvement, translating Martín Fierro earned Folco Testena a cultural credential within
\end{abstract}


an environment of political censorship and hostility toward foreigners. The objective of this article is to increase the availability of a text of limited access and to make a contribution to the history of translation with a focus on the social subjects involved in the task.

Keywords: Self-Figuring; Martín Fierro's Translations; Folco Testena; Nosotros Magazine; Italian Migration

\section{Testena y Nosotros, una amistad perdurable}

Comunardo Braccialarghe (Macerata, 1875-Buenos Aires, 1951), quien debe su nombre a la filiación de su padre a la Primera Internacional y devino en su juventud un agitador social y sindicalista, emigró a Buenos Aires en 1810 tras una condena por bancarrota fraudulenta. Con la discreta instrucción que le proveyó la escuela técnica interrumpida para trabajar como metalúrgico, devino periodista en esta ciudad bajo el seudónimo de Folco Testena y se convirtió en una de las figuras centrales de la prensa italiana en Argentina durante las tres décadas siguientes. Paralelamente a su labor como decano de la prensa extranjera en la cosmopolita capital porteña, Testena publicó y puso en escena varias piezas de teatro, tradujo numerosos textos literarios de diversos géneros y desarrolló su propia obra ensayística, poética y ficcional (Bertagna).

La relación de camaradería y colaboración entre Folco Testena y el grupo de intelectuales que se nuclearon en torno de la revista Nosotros (1907-1943) se extendió durante al menos un cuarto de siglo. Constan registros de sus primeras colaboraciones como traductor de poesía a partir de 1914. Bajo el título "Folco Testena y nuestros poetas", se introdujo a nuestro traductor ante el público de la revista invistiendo la que sería la figura que asumiría predominantemente en la publicación durante las próximas décadas, la de difusor de las letras nacionales:

Queremos dejar constancia en estas páginas de una nota muy simpática y muy halagüeña para nuestras letras [...] 
Testena ha querido últimamente que el público italiano aquí residente conociese y amase nuestra poesía nacional, y con gusto excelente y arte seguro, ha traducido al italiano dos bellos poemas aparecidos en los números anteriores de Nosotros (Nosotros (a) 209).

En el mismo número se celebran los esfuerzos de Testena por difundir la literatura local publicando traducciones de poetas argentinos en La Patria degli italiani y brindando conferencias sobre autores nacionales en círculos de origen porteño. Nosotros, en ocasiones, republicaba sus traducciones al italiano aparecidas en otros medios.

La función de difusor de las letras nacionales sería asumida por Testena entre los italianos residentes en Argentina, desde un principio, y en la madre patria, más adelante, durante las sucesivas temporadas en que habría de regresar por diversos motivos. Esta extensión de su campo de acción fue celebrada por el círculo nucleado en torno a la revista en numerosas oportunidades. Por ejemplo, en 1926, cuando estaba a punto de partir hacia Italia, se publicó bajo el título "Folco Testena" una breve nota alusiva:

Esta ausencia de Testena de nuestro país seguramente no será definitiva. Está ya demasiado vinculado a nuestro medio artístico y periodístico para que pueda permanecer alejado de él mucho tiempo. Mientras dure su ausencia se mantendrá en contacto con nuestro país, colaborando en Nosotros, La Razón, El Hogar, Mundo Argentino y otras publicaciones. Además en Italia, en su editorial Atlantide, continuará publicando traducciones de nuestros mejores poetas y dramaturgos y hará lo posible por obtener que las compañías dramáticas italianas representen estas traducciones (Nosotros (c) 143-144).

Es en el seno de este proyecto intelectual colectivo que Testena encuentra una posibilidad para publicar su traducción del Martín 
Fierro. Editada por Nosotros, la primera traducción completa del poema de Hernández salió a la luz en Buenos Aires, 1919. La lengua meta fue el italiano y sus lectores principales formaban parte de la comunidad de extranjeros cuantitativamente más representativa en la Argentina de aquel entonces.

Nosotros, huelga recordar, había lanzado seis años antes la encuesta intitulada “¿Cuál es el valor del Martín Fierro?”, a partir de la cual había propiciado un debate público acerca de las lecturas nacionalistas propuestas, entre otros, por Leopoldo Lugones (Altamirano). Desde un punto de vista objetivo, podemos afirmar que la polémica inaugurada por Nosotros apuntó hacia la calidad estética y el potencial representativo de una identidad nacional en el poema de Hernández. Es de considerar, sin embargo, la hipótesis de que Nosotros se estuviera posicionando, en medio del contexto de reacción nacionalista que caracterizó el Centenario, en contra de la idea de que el elemento autóctono fuera el único y legítimo formador de la cultura nacional (Prisley).

\section{La melancolía del traductor}

En la introducción del Martín Fierro al italiano que acompaña la edición prínceps de 1919 y la reimpresión del año siguiente, Testena narra su primer contacto con la obra y la razón por la que decidió traducirla, permitiéndonos adentrarnos en su mundo interior. Citamos a continuación algunos fragmentos de este largo relato, que comienza con las percepciones Testena de durante el trayecto en tren que conectaba su pensión en el Tigre con su trabajo en Buenos Aires:

Replegado y arropado hasta las narices en un vagón donde estaba solo, diluía mi gran tristeza mirando con ojos indolentes la indolente lluviecita que caía en los jardines yermos que bordeaban la calle. El poco cielo, el poco campo, el poco río que podía ver más allá del cristal empañado 
tenían una expresión uniforme: el bostezo. ¡Esa ira contra ese escenario goteante que contaminaba mi melancolía! [...] Vivía en una pensión de una familia aragonesa [...] Me decían 'El señor callado'; a veces, cuando no los oía, decían, con poca reverencia hacia mi barba: 'El chivo callado'. De hecho, yo no hablaba nunca. Ni tenía nada para decir ni tenía interés en que me dijeran nada.

Una de las noches de descanso concedidas a los periodistas de Buenos Aires, regresé antes de la media noche. En el comedor estaban haciendo un barullo del diablo. De golpe se aquietaron y, poco después, oí desde mi habitación un acorde de guitarra, primero, y luego, una voz que cantaba a medio tono una especie de letanía desbordante de tristeza. El canto duró tal vez una hora: lento, uniforme, un poco litúrgico, un tanto fúnebre.

Al día siguiente la señora me dijo que eso que había cantado el ingeniero era el 'Martín Fierro'.

-Martín Fierro... ¿Y eso qué es?

La patrona no lo sabía tampoco.

El mismo día le pregunté a un abogado argentino qué era el Martín Fierro.

-Un bodrio- me respondió.

[...]

Decía entonces que una tarde regresaba del Tigre, de una isla del Abra Nueva, donde vivía y cultivaba una familia de colonos piamonteses, que me ofrecía una pequeña habitación limpia y casi desprovista de comodidades suplementarias: una cama, una mesa, una silla -todo lo que me hacía falta y me gustaba.

Quien de los dieciséis a los veintisiete años pasó todo ese tiempo en prisión, quien ha probado la melancolía de vivir más de un año entero sin poner un pie fuera de la celda de dos metros por tres, adquiere el hábito de la soledad y de la simplicidad monástica. Pasados dieciocho años, todavía hoy, si me encuentro solo en un lugar cerrado, aunque sea más grande, doy instintivamente tres pasos adelante y tres pasos atrás, como si estuviese aún encerrado entre las cuatro paredes de una celda de reclusión. 
Y en ese cuarto también lo hacía.

Esa gente de campo diestra y sencilla, engañada por ciertos detalles de un amigo muy benévolo, creía que yo iba allí a hacerme 'el poeta'. La verdad es que yo iba para poder llorar tanto cuanto me diese la gana.

[...]

Pero me he olvidado de nuevo del tren que me llevaba de vuelta a la capital. El tren se detuvo en la primera estación. Subieron dos señores que mantuvieron durante todo el trayecto una discusión que los dividía encarnecidamente.

Decía un señor:

'El Martín Fierro es un entramado inútil y dañino de versos mal tejidos, carente de fidelidad histórica, de veracidad psicológica, de evidencia de recursos descriptivos y de conocimiento filosófico; una mezcolanza que, tras haber tenido éxito entre todos los analfabetos, ahora lo tiene entre los letrados [...]'

Decía el otro señor:

'El Martín Fierro es una gran y original obra de arte que floreció en el alma de un poeta instintivo. Es una rapsodia épica que retrata con veracidad la última fase de la lucha y de la transición entre la Argentina colonial y la civil [...]' ¿Y qué puede hacer un pobre hombre después de haber oído tales discursos de dos señores que, como mínimo, debían ser muy cultos? En lugar de tomar el acostumbrado tranvía, me subí a una carrocita y fui directamente a la tienda de un librero donde con unos pocos centavos compré los dos librejos, El gaucho Martín Fierro y La vuelta, en una edición horrible. Terminado el trabajo nocturno, en lugar de recogerme leí de un tirón los 7260 versos; dejé pasar una decena de días rumiando la lectura; después la leí con mucha calma, canto por canto; y cuando la hube terminado, cuando me pareció que conocía a conciencia una obra tan extravagante, me di cuenta de que no era capaz de juzgarla. La aventura había terminado; los dos librejos fueron confinados en un gran cajón que se abría cada tanto para engullir libros que no serían nunca más leídos.

Pero la aventura en realidad no había terminado [...]. 
Una noche, tras haber despachado la última página del periódico, permanecí en mi oficinita. Había abierto un libro y me había puesto a... llorar. Muy fácilmente este relato de un eterno llorisqueo aburrirá a los lectores. Pero no es superfluo, creo, el recuerdo de esas lágrimas que, hoy, mientras escribo estas páginas de introducción al Martín Fierro, son perennes y me pesan todavía sobre el corazón como una roca.

Mi pequeña oficina se comunicaba internamente con el gabinete del director, quien entró sin que yo me diese cuenta, me palmeó la espalda, apoyó mi frente sobre su pecho, me acogió afectuosamente:

-Hijo, ahora basta. Si sigue así morirá de pasión y con el remordimiento de dejar a sus hijos crudos y desnudos. Usted puede y debe rehacer su vida. Un día le harán justicia. Todo lo que hasta ayer le dio a la política, déselo al arte. Lo logrará. Hay un trabajo por hacer que valdrá por una vida: traducir a nuestra lengua el Martín Fierro. [...] $\mathrm{Si}$, como estoy seguro, usted lo logra, no habrá nada más que se pueda pedir por su orgullo de artista. Argentina le deberá mucho e Italia le deberá todavía más. ¿Estamos de acuerdo? Y ahora vayamos a tomar un café con leche y, después, a dormir.

Quizás mi buen colega no creía tanto ni en mis aptitudes ni en mi orgullo de artista; mucho menos en que Italia y Argentina le pudiesen dar valor a las aventuras de una traducción poética. Pero, sabiéndolo y conociéndome, y no pudiendo aliviar mi dolor, fui capaz de transformarlo (Testena (a) 5-7, traducción nuestra).

\section{La autofiguración del traductor}

El extrañamiento que produce el relato en primera persona de Testena se debe a que, en general, los traductores son sujetos de la enunciación sobre los cuales se suele dejar el menor rastro posible. Este fenómeno es denominado the translator's invisibility por la 
consagrada tesis de Lawrence Venuti (1996). Considerando que la introducción es un umbral estratégico que antecede y orienta la lectura, es absolutamente infrecuente y muy significativo que en este lugar, donde se dirimen los sentidos del texto traducido y que constituye un espacio disputado durante la proyección de una publicación (Genette), el traductor hablara de sí en clave autobiográfica.

A su vez, se ha demostrado que el artificio retórico de la captatio benevolentiae es la solución más habitual que los traductores encuentran frente a la omnipresente sospecha que sobrevuela la traducción como hecho del lenguaje -su imposibilidad de realización absoluta- y el prejuicio que recae sobre el traductor -traduttore traditore- (Carneiro). Testena, en cambio, desnudó crudamente su identidad -en un juego entre verdad y ficción, no podemos olvidarlo- y construyó, así, su autofiguración a través de un relato compuesto de episodios autobiográficos donde los esfuerzos del traductor se enmarcan en una historia de superación personal. De esta forma, el relato se edificó sobre la necesidad de sobreponerse a una melancolía, que no es aquella producto de la paradojal consciencia de la imposibilidad de una traducción absoluta (Lages); sino que se trata de una melancolía anterior y de la que Testena pudo reponerse gracias a la traducción del Martín Fierro. Como el protagonista, que “con el cantar se consuela” (Hernández 99), nuestro traductor afirma: "no pudiendo aliviar mi dolor, fui capaz de transformarlo". Hacer suyas las palabras de denuncia y lamento del poema se convirtió en una forma de exorcizar la melancolía.

La identificación entre el protagonista del relato de Testena con el héroe del poema es producto, asimismo, de ciertas evocaciones del texto traducido que han contaminado el relato de autofiguración del traductor. Es el caso de las impresiones de quien ha experimentado el encarcelamiento, rememoradas por el hijo mayor de Martín Fierro en el canto 12 de La vuelta; y la referencia a la desventura de los huérfanos, resultado de la injusticia social, descriptos como "pichones/sin acabar de emplumar" (Hernández 148).

Testena intercaló en su relato, asimismo, distintas valoraciones de la obra de Hernández. Es a través de una serie de personajes y 
de sus opiniones que el lector italiano pudo reconstruir una imagen multifacética del poema. En este sentido, es interesante observar que el primer contacto que se estableció con la obra en el relato de Testena es oral. "Lento, uniforme, un poco litúrgico, un tanto fúnebre" se presentó a los oídos el canto entonado ritualmente, como si el estado anímico del recién llegado hubiese impregnado la escena de la pensión, o como si todos los recuerdos reconstruidos por Testena sobre sus primeros contactos con el poema sintonizaran con el tono del lamento preponderante en la obra (Ludmer).

A este contacto inicial se suman otras valoraciones que van desde el conocimiento superficial que expresa la patrona aragonesa al gesto con el que el abogado desprestigió el poema, calificándolo como "un bodrio"; así como las posturas irreconciliables sobre la obra de los señores "como mínimo muy cultos". Acerca de la función de estas opiniones, podemos aventurar que Testena intentó recrear en su relato las distintas valoraciones que sobre el poema coexistían en aquel entonces. Este gesto, sin embargo, lejos de comprender una búsqueda de neutralidad de parte del traductor, debe ser estudiado con mayor profundidad para así evidenciar los sesgos hacia la obra que puedan haber influenciado su recepción.

Por último, es posible rescatar algunas señas acerca de coyuntura social del relato, que comienza siete años antes de la publicación de la traducción; es decir, dos años después de la llegada de Testena a Buenos Aires, en plenos festejos del Centenario, y en un contexto de reacción xenofóbica. Sobre este punto, una de nuestras hipótesis es que, a través de lo que entendemos como un gesto de protección, el jefe le entregó a Testena un remedio para su melancolía que es, a la vez, un pasaporte cultural o "credencial de ciudadanía" que le permitiría "integrarse con derechos plenos en el creciente torrente de la vida social" (Prieto 18).

Esto se debe a que en dicha década los debates que se ocuparon de las problemáticas sociales potencializadas por la migración masiva se encauzaron hacia dos discursos nacionalistas diferenciados. Uno de ellos contemplaba la inclusión del inmigrante en el proyecto nacional, como lo imaginaba Ricardo Rojas. El bastión llevado 
por Manuel Gálvez y seguido por Lugones, en cambio, excluía el elemento extranjero (Ferrás). En este debate, el Martín Fierro ocupaba un lugar central, ya que fue la obra a partir de la cual se disputaron los sentidos de lo nacional y, donde, además, se jugaban representaciones de los inmigrantes, especialmente de los italianos. Por esta razón, sería difícil sostener que la elección del Martín Fierro fuera casual. ${ }^{1}$

Nuestra segunda hipótesis es que este relato de autofiguración cobra un sentido particular dentro del contexto de la revista Nosotros, que para Gálvez representaba "el advenimiento de los descendientes italianos a las letras argentinas" y que promovió "formas de ingreso en el mundo cultural del grupo de jóvenes" (Delgado 17) que la llevaban adelante. En la vereda de enfrente del nacionalismo excluyente, Nosotros convocó a Testena como colaborador de la revista, divulgó la publicación de las obras de su autoría, alentó el designio que se había propuesto como difusor de las letras argentinas durante sus estadías en Italia y publicó su traducción de Martín Fierro en Buenos Aires en 1919 y 1920. La magnitud con la que el reconocimiento concedido por Nosotros a Testena incidió en su proyección dentro del campo literario puede verificarse en el agradecimiento que enunció con sus propias palabras:

Gracias, señores, por su iniciación: el trovador italiano, más viejo que todos vosotros, por la edad y los dolores, se enorgullece de haberos consagrado, durante cinco años, lo mejor de su poco ingenio, y será recompensado si logra, como vivamente espera, ser un día no demasiado distante el halo que una los poetas de Italia y de Argentina, los unos y los otros hijos de dos florecientes ramas de la noble Roma. [...]

Yo persistiré en la dulce fatiga de vivir las horas, los segundos de reposo rodeado de vuestros libros; y será para

\footnotetext{
${ }^{1}$ En un gesto menos radical, pero con efectos semejantes para la construcción de su figuración de traductor, Walter Owen, escocés residente en Buenos Aires, publicó la primera versión del Martín Fierro al inglés en 1935 (Iriarte).
} 
mí como el cumplimiento de un deber, y me parecerá con ello pagar un poco del mío a esta tierra de vosotros que le dio a mi espíritu inquieto la caricia de su cielo y me dio y me da el pan para mis hijos (Nosotros (b) 105-106, traducción nuestra).

\section{A modo de conclusion}

La autofiguración de Testena fue sedimentada a través de varias intervenciones discursivas a lo largo de los años en que desarrolló su labor como periodista, poeta y traductor en Buenos Aires. En el discurso de agradecimiento citado, de 1915, al igual que en la introducción al Martín Fierro de 1919, se enfatizaron las adversidades a las que Testena debió hacer frente y la deuda que asumía tener con el país que lo acogió. Es en función de dicha deuda que Testena construyó su autofiguración de denostado difusor de las letras argentinas; argumento que le sirvió además, a través de un gesto de humildad, para enunciar las ambiciosas proyecciones que cobijaba para su carrera.

La traducción al italiano del Martín Fierro realizada Folco Testena es hasta el presente la más reeditada, a pesar de las innumerables críticas de la que fue objeto y de las nuevas traducciones del Martín Fierro que fueron publicadas a uno y otro lado del océano. ${ }^{2} \mathrm{~A}$ pesar de la popularidad de esta traducción, el largo relato en primera persona

2 Ordenadas cronológicamente de acuerdo con sus primeras ediciones, las traducciones completas al italiano son: Folco Testena, seudónimo de Comunardo Braccialarghe, (Buenos Aires, 1919 y Milán, 2013); Mario y Venanzio Todesco (Padua, 1959), versión en prosa; Crocitto Cuonzo (Bahía Blanca, 1972); Giovanni Meo Zilio (Milán, 1977 y Buenos Aires, 1985) y Paolo Girosi (Buenos Aires, 1996). Existen también tres traducciones a lenguas y dialectos italianos: al piamontés, a cargo de Francisco Tosco (Rafaela, 1976); al sardo, autoría de Antonio Vargiu (Selargius, 2005); y al véneto, de Franceso Testa (San Jorge, 2009). Una nueva traducción a cargo de Paola Martini (Ceo Edizioni) se encuentra en preparación para ser publicada este año en Italia a través del "Programa Sur" de incentivo para la traducción de obras literarias argentinas. 
aquí analizado fue excluido de la tercera edición de la traducción, publicada también en Buenos Aires, pero esta vez por iniciativa de la comunidad italiana residente en la ciudad. Esto se debió a que el traductor, tras una década, revisó su primera traducción y consideró que había "salido a la luz cargando el peso de un proemio larguísimo, henchida de melancolía y de consideraciones críticas más presuntuosas que sólidas" (Testena (b) s/p).

El autor de la primera traducción completa del Martín Fierro, centenaria, falleció el 26 de marzo de 1957 en Buenos Aires. Pueden oírse ecos de la autofiguración de nuestro traductor en la publicación que a propósito de sus honras fúnebres preparó uno de los principales periódicos del país y que citamos a modo de colofón:

La calle Corrientes, destino de muchos de los antiguos gestos de Folco Testena y ámbito de su más viva resonancia de ayer, vio hace poco en el amplio sombrero y en las barbas luengas, ya plateadas, de este hombre itálico a un europeo recién traído por la marea de la guerra. El gentío, que en otro tiempo lo identificaba desde lejos, deteniéndose para observar su apostura, habíase transformado en multitud y ésta nada sabía de quien en el pasado pudo creer, no sin razón, que se presentaba ante la ciudad como desde un proscenio. Aunque su figura pertenecía hoy a la memoria de minorías, su recuerdo gravitará, no obstante, en muchas páginas de la historia -o de la pequeña historia- literaria y artística de Buenos Aires (La Nación s/p).

\section{Referencias}

Altamirano, Carlos. "La fundación de la literatura argentina". Ensayos argentinos. De Sarmiento a la vanguardia. Buenos Aires: Ariel, 1997 [1983]: 201-210. 
Bertagna, Federica. La stampa italiana in Argentina. Roma: Donzelli Editori, 2009.

Carneiro, Teresa. Contribuições para uma teoria do paratexto do livro traduzido: caso das traduções de obras literárias francesas no Brasil a partir de meados do século $X X$. Tesis de doctorado. 2014. Disponible en: https://www.maxwell.vrac. puc-rio.br/29928/29928.PDF. Acceso en: 9 de diciembre de 2020.

Delgado, Verónica. El nacimiento de la literatura argentina en las revistas literarias. Tesis de doctorado. UNLP, 2006. Disponible en: < http://sedici.unlp. edu.ar/handle/10915/3067 > . Acceso en: 9 de diciembre de 2020.

Ferrás, Graciela. Ricardo Rojas: nacionalismo, inmigración y democracia. Buenos Aires: Eudeba, 2017.

“Folco Testena. Falleció ayer en esta capital”. La Nación. 27. 03-1951. s/d.

"Folco Testena". Nosotros. 54, 1926. "Notas y comentarios": 143-144. Disponible en: https://www.revistas-culturales.de/es/digitale_sammlungen/ seite $/ 282470$ ?page $=0 \% 2 \mathrm{C} 148$. Acceso en: 9 de diciembre de 2020 .

"Folco Testena y nuestros poetas". Nosotros (a). 67, 1914. "Notas y comentarios": 203. Disponible en: https://www.revistasculturales.de/es/digitale_sammlungen/ seite/276597? page $=0 \% 2 \mathrm{C} 208$. Acceso en: 9 de diciembre de 2020 .

Genette, Gerard. Umbrales. Traducción de Susana Lage. Ciudad de México: Siglo XXI, 2001 [1987].

Hernández, José. Martín Fierro. Edición crítica de Élida Lois y Ángel Núñez Coord. Madrid: Scipione, 2001.

Iriarte, Sara J. "Walter Owen, traductor de Martín Fierro". Estudios de Teoría literaria. Revista digital: artes, letras y humanidades. 6. 12 (2017): 89-97. Portal de revistas de la UNMDP. Disponible en: < https://fh.mdp.edu.ar/revistas/index. php/etl/article/view/2263/2417 > . Acceso en: 9 de diciembre de 2020 . 
Lages Kampff, Susana. Walter Benjamin, Tradução e melancolia. São Paulo: Edusp, 2002.

Ludmer, Josefina. El género gauchesco. Un tratado sobre la patria. Buenos Aires: Eterna Cadencia, 2012 [1988].

Prieto, Adolfo. El discurso criollista y la conformación de la Argentina moderna. Buenos Aires: Siglo XXI, 2006 [1988].

Prisley, Leticia. "Nosotros. Revista de letras, arte, historia, filosofía y ciencias sociales". Diccionario Enciclopédico de las Letras de América Latina. Caracas: Fundación Biblioteca Ayacucho, 1996: 3395- 3400

Testena, Folco. “Ai poeti argentini nei di della festa argentina”. Nosotros 75(b), 1915. "Comidas de Nosotros": 105-106. Disponible en: https://www.revistasculturales.de/es/digitale_sammlungen/seite/276540?page $=0 \% 2 \mathrm{C} 109$. Acceso en: 9 de diciembre de 2020 .

Testena, Folco(a). "Il perchè di questa traduzione". In: Hernández, José. El gaucho Martín Fierro y La vuelta de Martín Fierro. Poemi creoli tradotti in versi italiani da Folco Testena. Buenos Aires: Nosotros, 1919, p. 5-14.

Testena, Folco(b). "Introducción”. In: Hernández, José. Martín Fierro. Versione italiana di Folco Testena. Buenos Aires: Imprenta Fontana, 1930. s/p.

Venuti, Lawrence. The Translator's Invisibility. New York: Routlegde, 1996.

Recebido em: 19/12/2019

Aceito em: 22/03/2020

Publicado em maio de 2020

Sara Jaquelina Iriarte. E-mail: sarajiriarte@gmail.com. ORCID: http://orcid. org/0000-0003-2584-2848. 